\title{
Detection of fatigue damage in long-span reinforced concrete structures
}

\author{
Igor Rubtsov ${ }^{1, *}$, Ramidin Alisultanov ${ }^{1}$, Alexander Zinatullin ${ }^{1}$, and Nikolay Midrigan ${ }^{1}$ \\ ${ }^{1}$ Moscow State University of Civil Engineering, Yaroslavskoe shosse, 26, Moscow, 129337, Russia
}

\begin{abstract}
The emergency situations and catastrophes with buildings and structures may be caused by both the short-time loads considerably exceeding the design load values and the cyclic loads exciting the fatigue damage in the structure material. The cyclic influence is characterized by the amplitude, the cycle asymmetry and the number of loading cycles. To reveal all the factors of a cyclic influence is possible by the on-line measurement of stresses or that of strains at the structure under observation.
\end{abstract}

\section{Introduction}

This work describes a methodology of processing of observations of the strains in longspan dome structures. The observations of the strains at the points on the internal dome surface were carried out with the use of a robotized tachymeter during a four-year period with an interval of 15 minutes to 2 hours. The study considered 5580 measurement results obtained for 8 months and revealed 1598 strain cycles. The authors used different information processing methods including some one-parameter methods (extreme methods, maximum methods, consolidated swing methods) and a two-parameter method considering not only the cycle amplitude but also the average cycle stress. The work contains the functional dependences allowing the determination of the degree of fatigue damage of the structure. All the strain cycles and, respectively, the cycles of stress changes have been divided into 18 groups. For every group, the number of loading cycles as well as the degree of fatigue damage has been determined. The analysis of the data obtained proved that the determination of fatigue damage in the structures requires the consideration of all swing groups. The consideration of only maximum swing groups leads to nearly double underestimation of the degree of accumulated damage. The authors estimated that the degree of accumulation of fatigue damage may achieve its ultimate value for the design maintenance period of the structure concerned equal to 50 years.

\section{Review of references}

The modern construction requires a continuous improvement of technologies concerned including the methods of evaluation of construction projects contributing to the reduction of

\footnotetext{
* Corresponding author: AlisultanovRS@mgsu.ru
} 
specific consumption of materials, time and cost of erection of structures [1]. The prediction maintenance period of many buildings and structures may be 100 and more years long. In this case, the cyclic loads become determinant ones for the structural design procedures.

The consideration of cyclic loads still remains unclear [2]. This is connected with an insufficient supply of experimental studies of actual cyclic loads influencing buildings or structures. The valuable information may be obtained through systematic observations of buildings and structures [3,4]. The structural damage detected during the process of instrumental inspection allow us to evaluate the state of the structure [5] and the risks of its further operation $[6-8]$ as well as to reveal the most vulnerable places for the purpose of installation of systems of continuous or quasi-continuous monitoring there [9].

The monitoring process may be performed with the use of different methods: the thermal pressure deformation method [10], the acoustic method [11], the standing wave method [12], the vibration diagnostics method [13], the dynamic method [14], etc. One of the most popular way of determination of stress-and-strain state of structural elements and structures is the tensometry method based on fiber-optic sensors [15-24].

The most reliable methods are the methods based on direct measurements of strains, that is the geodetic methods. Two of them are the method of range line measurements [25] and the method of three-dimensional survey of structure strains with the use of laser scanner or of high-precision tachymeters [26]. The questions of geodetic monitoring of long-span structures have been studied in the work [27].

The geodetic methods allow us to observe the structure with the periodicity of several minutes. The guidance time for the robotized tachymeter TCRA 1201+ (Leica) is about 6 seconds. Thus the observation of 150 points located on a long-span structure takes us 15 minutes.

The structural strains may be connected not only with the changes in the material of support structures, but also with changed loading conditions inside the building and with external effects caused by wind, snow or ambient temperature. The periodicity of these effects (excluding some short-time actions) is usually not less than one hour. The change in the loading conditions causes the change in mechanical stresses in the structures and leads to the mechanical fatigue of these structures [28, 29, 31].

The purpose of the study is the determination of the degree of influence of actual strains and corresponding mechanical stresses in the structure during its maintenance period on the process of accumulation of fatigue damage.

The values of strains and mechanical stresses in the structure material have been obtained for all the cycles on the basis of the hypothesis of direct proportionality of the strains to the stresses.

\section{Materials and methods}

This work considers the method of three-dimensional geodetic observations of nonstationary periodic processes causing the changes of mechanical stresses in the material of the structure, i. e. its mechanical fatigue.

The researchers from NIU MGSU carried out three-dimensional tachymetry survey of strains in a shell roofing structure with the curvature of two kinds and with the $45 \mathrm{~m}$ long span for four years. The procedure used a robotized tachymeter with the periodicity of one hour. Fig. 1 shows the graph of the vertical strain values for one of the central points of observation for the time period from 29.12.2009 till 31.12.2009 equal to 48 hours. The graph includes 48 measurement points representing hour-long vibrations of the structure. 


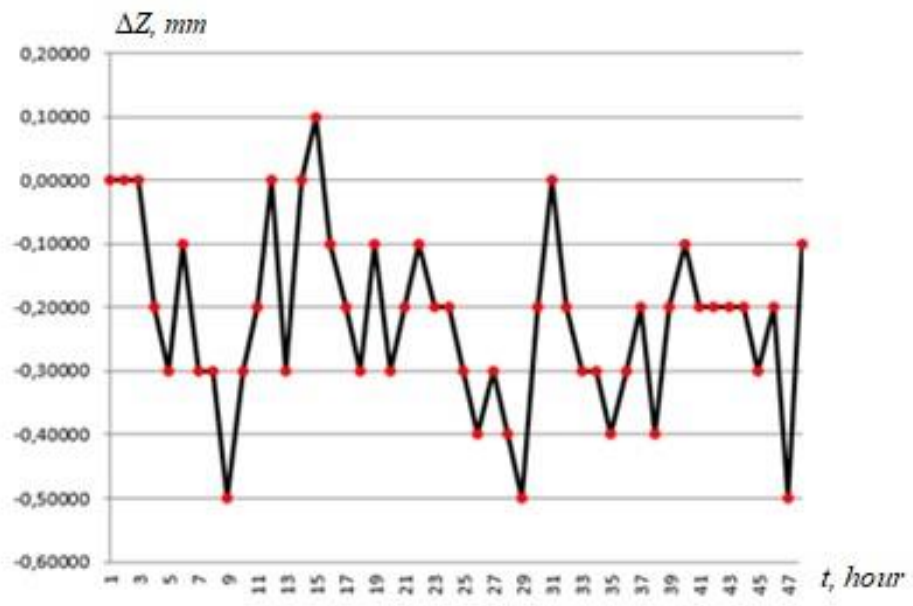

Fig. 1 Vertical vibrations in the central part of the dome shell with consideration of all the measurements

The study of the influence of structural strains on the mechanical fatigue of the material of the structure, in particular, on the mechanical fatigue of the reinforcement steel, was based on the substitution of the stochastic loading process by some schematic process. This process should be equivalent to the actual process with respect to the level of accumulated fatigue damage. There are different schematization methods: extreme methods, maximum methods, swing methods, consolidated swing methods, total cycle methods, etc. [30]. The irreversible changes are connected only with a loading cycle, so we could dismiss all the intermediate points from consideration and retain only extreme points. The schematic graph is presented in Fig. 2.

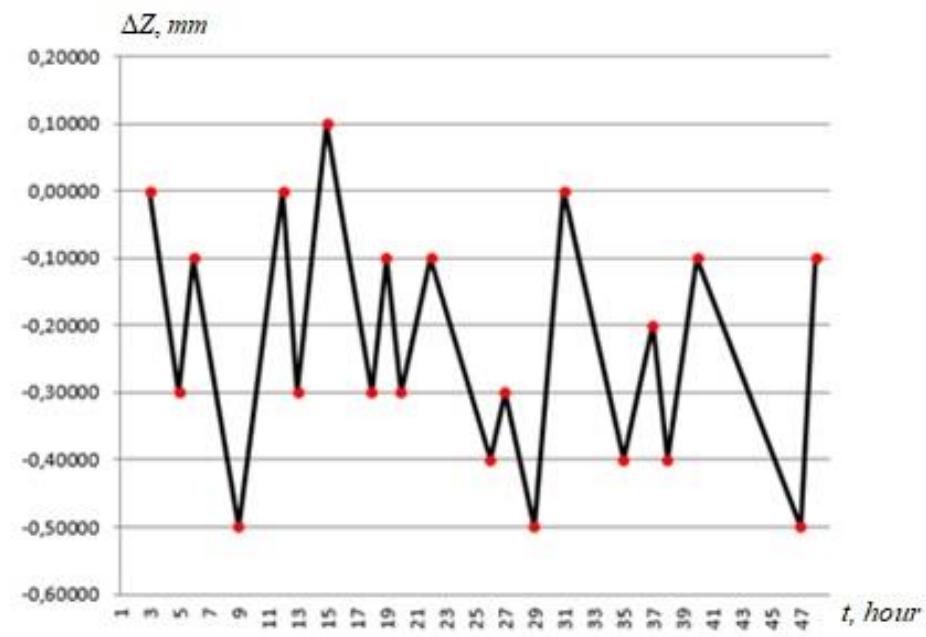

Fig. 2 Vertical vibrations in the central part of the dome shell excluding the intermediate points

The aforesaid methods of schematization of the stochastic loading process are based on a one-parameter systematization, which considers only one parameter: the stress amplitude. A more complete parametrization is a two-parameter one, which provides for the consideration of the stress amplitude and the average stress for every cycle. To consider 
the cycle asymmetry, we can use the equivalent amplitudes reduced to a symmetric-stress cycle [32]

$$
\sigma_{a_{r e d}}=\sigma_{a}+\psi_{\sigma} \sigma_{m}
$$

The cycle asymmetry efficiency is calculated through the formula

$$
\psi_{\sigma}=\frac{2 \sigma_{-1}-\sigma_{0}}{\sigma_{0}}
$$

where - fatigue limit for a symmetric-stress cycle, - fatigue limit for a pulsating-stress cycle.

The amplitude and the average value for the i-th point are determined by the formulas

$$
\begin{gathered}
\sigma_{a_{i}}=\left|\frac{\sigma_{i}-\sigma_{i+1}}{2}\right| \\
\sigma_{m_{i}}=\left|\frac{\sigma_{i}+\sigma_{i+1}}{2}\right|
\end{gathered}
$$

Taking into consideration the data concerning the fatigue limit values for both the pulsating-stress cycle and the reverse-stress cycle for various structural steel grades [24], we can conclude that the values are within the range from 0.35 to 0.5 . The work [25] recommends to take the values within the range from 0.05 to 0.3 . In this connection, we will use the values from 0.1 to 0.4 in our further calculations.

With non-stationary loadings, the design of the structure is carried out with the equivalent stress , the action of which is equivalent to the effect of all actual stresses. The equivalent stress value is determined by the formula [28 - 30]

$$
\sigma_{e q}=\sqrt[m]{\frac{1}{N_{0}} \sum \sigma_{a_{r d i}}^{m} n_{i}} \leq \sigma_{\max }
$$

where - number of cycles determined by the inflection point at the fatigue curve (it is usually taken within the range: ); - maximum permissible stress level; - total number of loading cycles with the stress value determined by the formula (1); - exponent of the power for the fatigue curve (it is usually taken equal to 9). The equivalent stress values in loading cycles are different, therefore the formula (3) may be presented in the form

$$
\sigma_{e q}=m \sqrt{\frac{1}{N_{0}} \sum \sigma_{a_{r d i}}^{m}} \leq \sigma_{\max }
$$

The comparison of the geodetic survey data (Fig. 1) with the stresses in the structure is possible only with the assumption of direct proportionality of displacements and stresses. This assumption may be expressed in the form

$$
\sigma=a(b-z)
$$

where a - proportionality factor, $b$ - coordinate value corresponding to a limp state of the structure, $\mathrm{z}$ - running coordinate. The $\mathrm{b}$ values are taken in accordance with the assumption of possibility of achievement of maximum self-weight deflection of the structure and of maintenance loads at the moment of study; the a values are taken from the assumption that the stresses may achieve the value of for the maximum deflection of $b$. In this work we take $\mathrm{a}=0.176 ; \mathrm{b}=100$. All the calculations have been carried out for the strength characteristics corresponding to the St3 steel grade. Since the temperature under the shell was permanent, we could assume that there was no influence of the temperature on the stress-and-strain state of the roofing structure.

The aforesaid assumptions allow us to perform the conversion of vertical displacements of dome shell points under observation to mechanical stresses in the dome shell structure. Thus, we can analyze, from the point of view of accumulation of fatigue damage, the whole set of data concerning the dome deformations obtained during the time period from 
01.10.2011 till 01.06.2012, which was 8 month long. In all, we performed 5880 measurements, which allowed us to reveal 1598 strain cycles.

\section{Results}

One of the problems described in this study is the problem of study of the influence of the stress swing value in the loading cycles on the accumulation of fatigue damage. For the solution of this problem, the stress swing values have been obtained for all the loading cycles. The maximum swing value was equal to $175.9 \mathrm{MPa}$. Since the yield strength for the St3 steel equals 245MPa (GOST 380-2005), we can conclude that all the loading cycles operate within the elasticity range for the reinforcement steel, and the damage appears because of a polycrystalline non-uniform structure of the metal, which causes different stresses in crystalline grains. This non-uniformity of the material structure and that of the stresses in it causes the plastic deformations in crystalline grains already at early stages of the deformation process [30]. Then the maximum swing was divided into 18 groups, hence the swing of every group was equal to $9.77 \mathrm{MPa}$. For every group, we determined the number of loading cycles corresponding to the interval of stress values for this group (Table 1). The group 1-18 includes all the measurement cycles, i. e. all the cycles with the stress values of 0 to $175.9 \mathrm{MPa}$, the group 1-17 includes the cycles with the stress values of 0 to 166.1 MPa, the group 1-2 - the cycles with the stress values of 0 to $19,5 \mathrm{MPa}$ and the group 1 - the cycles with the stress values of 0 to $9.77 \mathrm{MPa}$. The obtained data are expressed in the form of a bar graph (Fig. 3) as well. The bar graph shows the number of loading cycles in every group. The group 1 contains 529 cycles; the group 2 contains $1017-529=488$ cycles; the group 3 contains 270 cycles; the group 17 contains 2 cycles and the group 18 contains 4 cycles.

Table 1. Number of loading cycles in different swing groups

\begin{tabular}{|c|c|c|c|c|c|c|c|c|c|c|c|c|c|c|c|c|c|c|}
\hline Group number & $\stackrel{\infty}{\sim}$ & $=$ & $\stackrel{0}{-}$ & $\cong$ & \pm & $\underline{\sim}$ & $\simeq$ & $=$ & $\circ$ & $a$ & $\infty$ & $r$ & 6 & in & t & m & $N$ & - \\
\hline $\begin{array}{l}\text { Number of points in } \\
\text { the group }\end{array}$ & $\stackrel{\infty}{2}$ & 竞 & กิ & 욤 & $\begin{array}{l}\infty \\
\infty \\
\end{array}$ & $\begin{array}{l}\text { D) } \\
\stackrel{n}{n}\end{array}$ & $\underset{n}{\mathbb{N}}$ & 占 & $\begin{array}{l}\stackrel{\circ}{\circ} \\
\stackrel{2}{n}\end{array}$ & 点 & $\stackrel{ \pm}{n}$ & \begin{tabular}{l}
$\infty$ \\
\multirow{2}{n}{}
\end{tabular} & 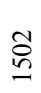 & 尽 & $\stackrel{\curvearrowleft}{\exists}$ & $\begin{array}{l}\widehat{\infty} \\
\stackrel{\Xi}{ }\end{array}$ & $\stackrel{ }{\circ}$ & ते \\
\hline $\begin{array}{l}\text { Upper limit value, } \\
\mathrm{MPa}\end{array}$ & $\stackrel{2}{I}$ & $\stackrel{8}{\circ}$ & $\stackrel{\circ}{\sim}$ & 卞 & $\underline{m}$ & $\widehat{\cong}$ & $\Xi$ & $\stackrel{\circ}{\circ}$ & $\stackrel{\infty}{\infty}$ & $\infty$ & $\stackrel{\infty}{\sim}$ & $\infty$ & in & gे & ले & ते & ¿ి & 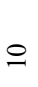 \\
\hline
\end{tabular}




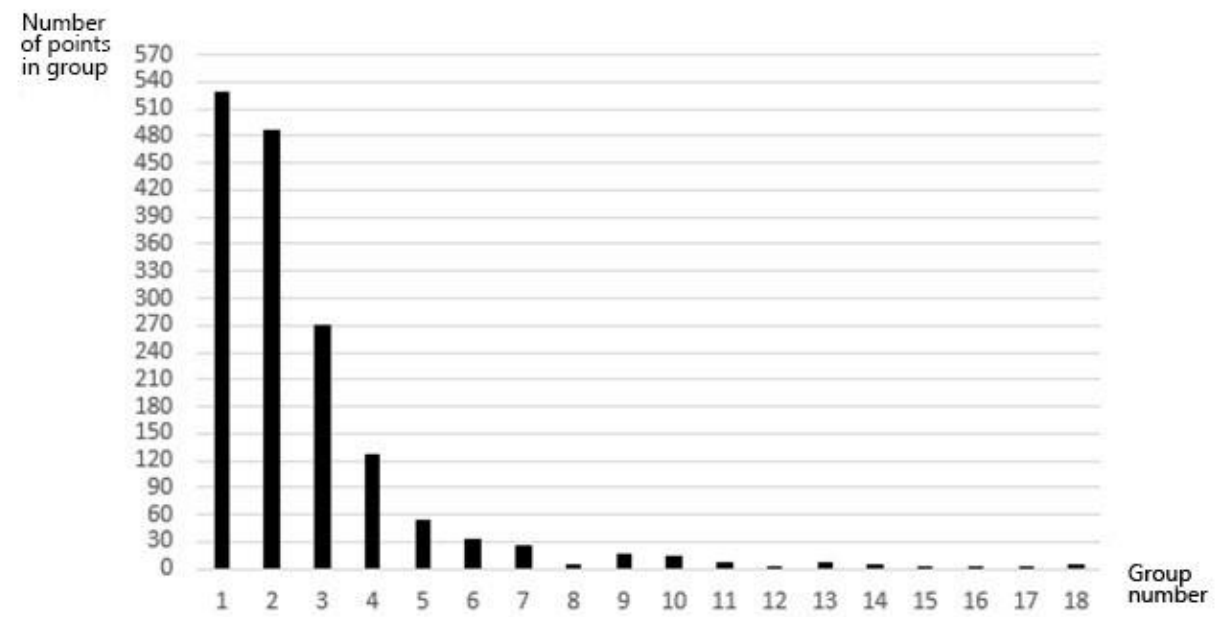

Fig. 3 Bar graph for the distribution of number of cycles in accordance with the swing amplitude

As it can be seen from the bar graph, the number of loading cycles sharply decreases going on from one swing group to the next swing group. But the damage values calculated through the formula (4) for every swing group still remain almost the same, which the corresponding bar graph shows (Fig. 4). More than that, the lesser swing values cause greater values of accumulated damage due to a greater number of them. Thus, for group 1 (average swing value of $4.88 \mathrm{MPa}$ ) and group 2 (average swing value of $7.33 \mathrm{MPa}$ ), the accumulated damage value is about $13 \mathrm{MPa}$, while for group 12 (average swing value of $112.4 \mathrm{MPa}$ ) the accumulated damage is about $7 \mathrm{MPa}$. Hence the consideration of all possible deformations is necessary.

$$
\sigma_{6} \mathrm{MPa}
$$

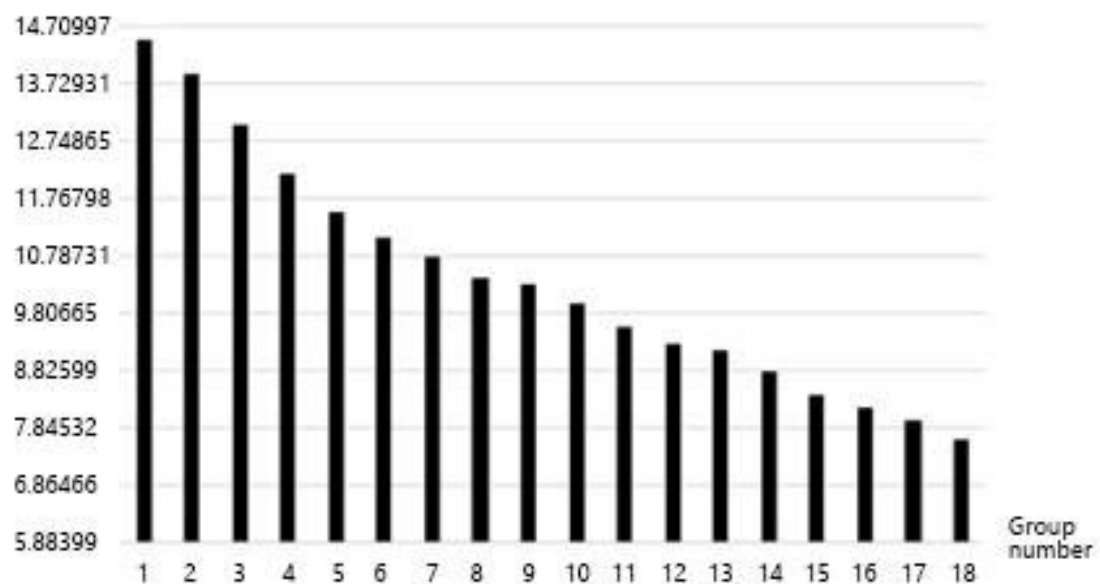

Fig. 4 Bar graph for the damage values for the swing groups with $\psi=0.2$

To prove this assumption, we have analyzed the equivalent damage values for the whole set of loading cycles for $\psi=0.1,0.2,0.3,0.4$. At first we considered only the group with the maximum swing amplitude (group 18). Then we considered two groups with the maximum swing amplitude in common (groups 17 and 18), then three groups (groups 16, 17 and 18), etc. (Fig. 5). 


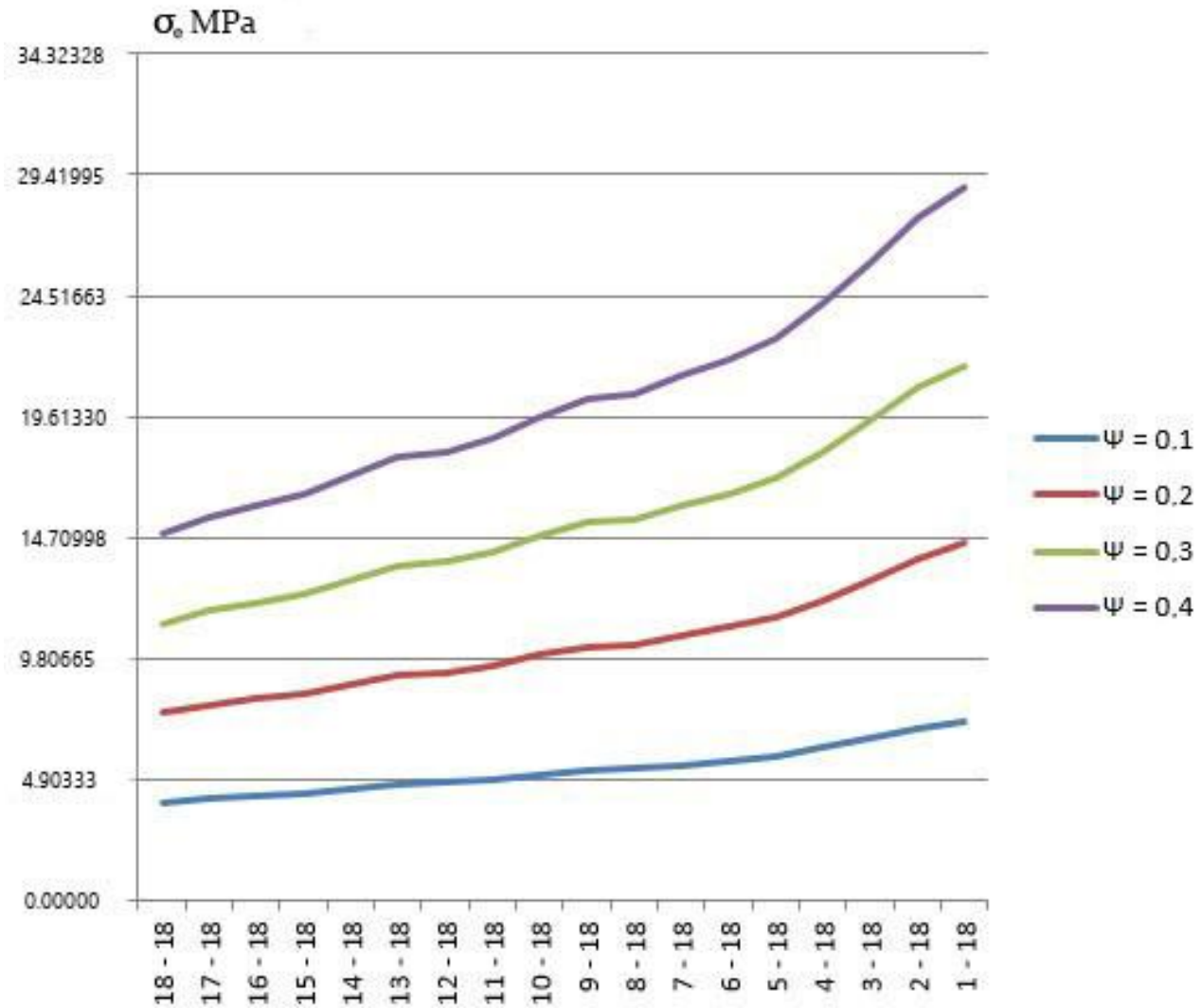

Fig. 5 Equivalent damage values for different sets of swing groups

The graph (Fig. 5) proves the aforesaid assumptions and allows us to formulate the final conclusion concerning the necessity of consideration of all the strain swings in the process of determination of fatigue damage values for the shell roof structure.

\section{Conclusions}

This study used the measurement data obtained for the dome shell during the time period of 8 months. The maintenance period for such structures is not less than 50 years. Assuming that the cyclic character of dome geometry changes is permanent during its service period, we can extrapolate the obtained data to the total maintenance period. Supposing in this case $n_{i}$ be the number of measurement intervals for the total maintenance period, we can easily get the value of $n_{i}=75$. In other words, the equivalent stress value for the total maintenance period will be by $\sqrt[9]{n_{i}}=1.62$ times greater. The equivalent fatigue damage for the total maintenance period of the structure will be equal to nearly $50 \mathrm{MPa}$, which can be compared with the material fatigue limit for a repeated-stress cycle. The study substantiated the possibility of the performance of systematic instrumental observations - the monitoring of changes of the stress-and-strain state in long-span reinforced concrete structures with the use of geodetic methods. The processing of measurement results should consider all the strains detected in the structure. In the process of further studies, it is expedient to consider the strains in many points on the surface of the structure under observation. The selection of 
the tachymetry interval will be discussed in further studies considering geometrical and strength parameters of the structure concerned.

All tests were carried out using research equipment of The Head Regional Shared Research Facilities of the Moscow State University of Civil Engineering (RFMEFI59317X0006).

\section{References}

1. A.A. Lapidus, A.N. Makarov Civ. Engin. Journ., 153, 378-383 (2016)

2. A.V. Korgin, M.A. Zakharchenko, M.V. Emel'yanov, V.A. Ermakov, I.V. Rubtsov, A.V. Kukhta MGSU Proceedings, 8, 212-221 (2011)

3. I.V. Rubtsov Integral, 5, 86-87 (2007)

4. I.V. Rubtsov Integral, 6, 102-103 (2007)

5. I.V. Rubtsov, G.E. Treskina, A.S. Bolotova Science revue, 18, 58-62 (2015)

6. A.G. Tamrazyan Monitoring of risks for structural elements of long-span structures (Prevent. of accidents with build. and struct., Magnitogorsk, 54-58, 2007)

7. S.V. Sat'yanov, P.B. Pilipenko, V.S. Kotel'nikov, N.P. Chetverik, V.A. Frantsuzov, A.G. Tamrazyan, A.I. Bedov Erect. and spec. works in constr., 3, 12-13 (2011)

8. A.G. Tamrazyan Proceedings of the Research Center "Constr.", 1, 160-171 (2009)

9. A.A. Volkov, I.V. Rubtsov MGSU Proceedings, 1, 208-212 (2013)

10. S.V. Bekhterev, A.B. Manukin, V.G. Minaeva, V.I. Rebrov Quest. of engin. seism., 35, 16-27 (2008)

11. K.Yu. Voichenko, E.Yu. Remshev, M.Yu. Silaev, A.N. Glushko Metal. process., 3, 1015 (2014)

12. A.A. Bakh, A.A. Krasnikov Seism. stable constr. Safety of struct., 7, 26-30 (2014)

13. M.I. Kadomtsev, A.A. Lyapin, Yu.Yu. Shatilov Don engin. bulletin, 3, 576-579 (2012)

14. S.N. Savin Civ. Engin. Journ., 7, 58-62 (2012)

15. I.V. Rubtsov, V.P. Neugodnikov, F.A. Egorov, O.I. Rubtsov, V.I. Pospelov Constr. mater., equipm. and techn. of the XXI c., 4, 46-47 (2005)

16. V.I. Pospelov, F.A. Egorov, A.P. Neugodnikov, I.V. Rubtsov, V.A. Bykovsky Constr. techn., 5, 52 (2005)

17. A.P. Neugodnikov, I.V. Rubtsov, F.A. Egorov New Urals Civ. Engin., 10, 42 (2004)

18. J.C Suárez, B. Remartınez, J.M. Menéndez, A. Güemes, F. Molleda Journ. of Mater. Proc. Techn., 143, 316-320 (2003)

19. Inaudi D. Application of Fibre Optic Sensors to Structural Monitoring (Trends in Optical Nondestr. Test. and Inspect., 459-472, 2000)

20. D. Inaudi, S. Vurpillot, N. Casanova, P. Kronenberg Smart Mater. and Struct. Journ., 7, 199-208 (1998)

21. B. Lee Opt. Fiber Tech, 9, 57-79 (2003)

22. D.C. Betz, G. Thursby, B. Culshaw, W.J. Staszewski Smart Mater. Struct, 12, 122-128 (2003)

23. N. Takahashi, A. Hirose, S. Takahashi Optical Review, 4, 691-694 (1997)

24. K. Satori, Y. Ikeda, Y. Kurosawa, A. Hongo, N. Takeda Proceedings SPIE, 3986, 104$111(2000)$ 
25. I.V. Rubtsov, M.S. Savin Science-and-Engin. Proceedings of the Volga Reg., 5, 283286 (2012)

26. I.V. Rubtsov, Yu.V. Andrusenko, M.S. Savin, M.V. Sryvkova Volga Reg. Scient. Journ., 1, 31-37 (2012)

27. I.V. Rubtsov, A.V. Kukhta, O.I. Rubtsov, A.M. Galushko MGSU Proceedings, 4, 329$334(2010)$

28. I.V. Rubtsov Evaluation of the intensity of fatigue damage on the basis of periodic geodetic observations (MGSU Proceedings, Moscow, 2013)

29. R.S. Alisultanov, A.V. Oleinikov, T.A. Pyatnitskaya, A.A. Lushnikov MGSU Proceedings, 4, 7-16 (2016)

30. S.V. Serensen, V.P. Kogaev, R.M. Shneiderovich Bearing capacity and strength analysis of machine parts ("Mashinostroenie", Moscow, 1975)

31. A. Pustovgar, A.Tanasoglo, I. Garanzha, L. Shilova, A. Adamtsevich, MATEC Web of Conferences, 86, 04003 (2016)

32. D.N. Reshetov Machine parts ("Mashinostroenie", Moscow, 1975) 